\title{
Isolated Plexiform Neurofibroma of Tongue
}

\author{
${ }^{1}$ Abhinav K Viramgama, ${ }^{2} \mathrm{HS}$ Umadevi, ${ }^{3}$ Kavita Rao, ${ }^{4}$ Priya Sanjeevarappa
}

\section{ABSTRACT}

Neurofibroma (NF) is a benign tumor of nerve tissue origin, derived from the cells that constitute the nerve sheath. Neurofibroma is seen either as solitary lesion or as a part of generalized syndrome neurofibromatosis (Von Recklinghausen disease of the skin). The solitary form does not differ from the disseminated form or the multiple form of the disease except that systemic and hereditary factors present in the disseminated form are absent in the solitary type.

We report a case of 60 -year-old female who visited the department with a complaint of painless swelling on the dorsal surface at the anterior one-third of tongue since 3 to 4 years. The lesion was excised under local anesthesia. Based on the clinical features, histopathological examination, and immunohistochemical analysis, the diagnosis of plexiform neurofibroma (PN) was given. Isolated PN is a rare tumor. The present case is an isolated $\mathrm{PN}$ of the tongue that was not associated with neurofibromatosis.

Solitary NFs rarely change into a malignant form. However, Steward and Bailey have drawn attention to the fact that it is important to know whether the tumor is benign or malignant before excision.

Keywords: Mast cells, Plexiform neurofibroma, Tongue.

How to cite this article: Viramgama AK, Umadevi HS, Rao K, Sanjeevarappa P. Isolated Plexiform Neurofibroma of Tongue. J Health Sci Res 2018;9(1):23-26.

Source of support: Nil

Conflict of interest: None

\section{INTRODUCTION}

The most common of the peripheral nerve tumors is the benign NF, derived from an admixture of Schwann cell and perineural fibroblast proliferation. Multiple lesions are seen in persons with Recklinghausen's neurofibromatosis (neurofibromatosis 1), and certain melanotic macules are considered by some to be a variant of NF. ${ }^{1}$ Under the classification given by Shklar and Meyer in 1963, it can be seen as a solitary lesion or multiple as a part of generalized syndrome of neurofibromatosis. ${ }^{2}$ Approximately $25 \%$ of

\footnotetext{
${ }^{1}$ Student (Third Year), ${ }^{2}$ Professor, ${ }^{3}$ Professor and Head, ${ }^{4}$ Reader

${ }^{1-4}$ Department of Oral and Maxillofacial Pathology, Vokkaligara Sangha Dental College \& Hospital, Bengaluru, Karnataka, India

Corresponding Author: Abhinav K Viramgama, Student (Third Year), Department of Oral and Maxillofacial Pathology Vokkaligara Sangha Dental College \& Hospital, Bengaluru Karnataka, India, Phone: +918026618066, e-mail: abhinav. viramgama@gmail.com
}

all NFs are found in the head and neck region. ${ }^{3}$ The literature reports that the frequency of solitary NFs in the oral cavity remains approximately $6.5 \%$, especially in lesions not associated with neurofibromatosis type 1 (NF-1). In the oral cavity, the preferential site is tongue, followed by buccal mucosa and lips, but it can also affect the gingiva, palate, major salivary glands, and maxillary bones. ${ }^{4}$

\section{CASE REPORT}

A female patient aged 60 years reported with a painless swelling on the dorsal surface at the anterior one-third of tongue since 3 to 4 years. Patient was apparently normal 3 to 4 years back when she noticed a swelling on her dorsal surface at anterior one-third of tongue, which now attained the present size of $2 \times 2 \mathrm{~cm}$.

Swelling was pale pink in color, ovoid in shape, pedunculated, located on the dorsal surface at the anterior one-third of the tongue (Fig. 1). On palpation, swelling was mobile and soft in consistency. Based on clinical examination, the provisional diagnosis of irritation fibroma was given. The mass was surgically excised and sent for histopathological examination. Tissue sections were stained with hematoxylin and eosin (H\&E) stain and Toluidine blue stain.

Microscopic examination of H\&E-stained sections showed hyperplastic parakeratinized stratified squamous surface epithelium (Fig. 2). Underlying connective was moderately dense fibrous interspersed with plump fibroblasts. Well-circumscribed, unencapsulated mass comprising of spindle-shaped cells with wavy nuclei admixed with small nerve fibers was arranged in diffuse pattern along with plexiform arrangement (Figs 3 and 4). Myxoid change was seen within a nodule. Mast cells were frequent. Mitotic activity was rare.

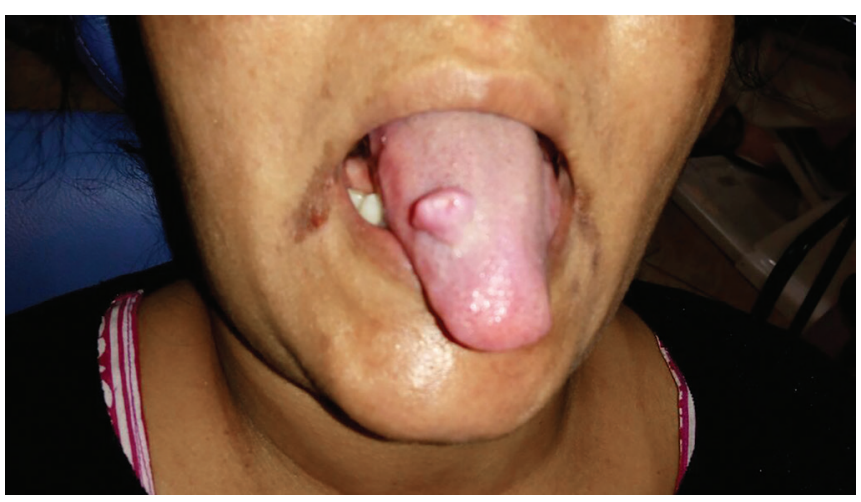

Fig. 1: Swelling on dorsum of the tongue 


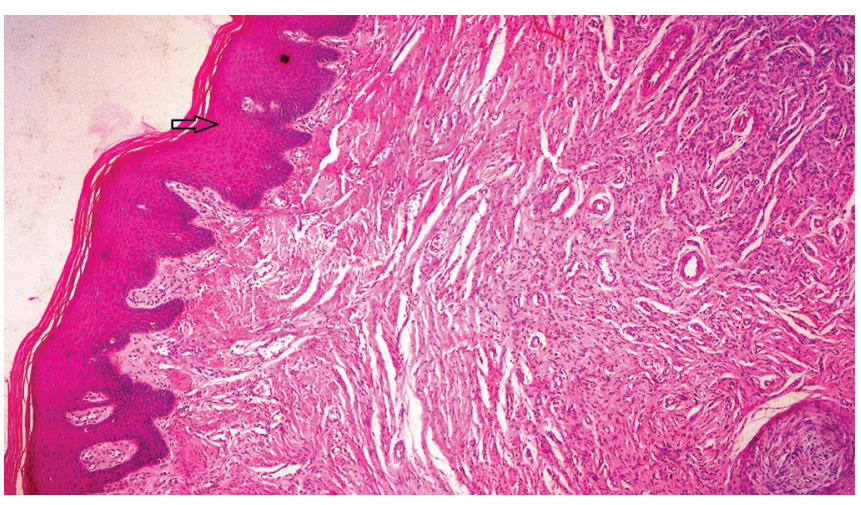

Fig. 2: Unencapsulated lesion with spindle cell proliferation

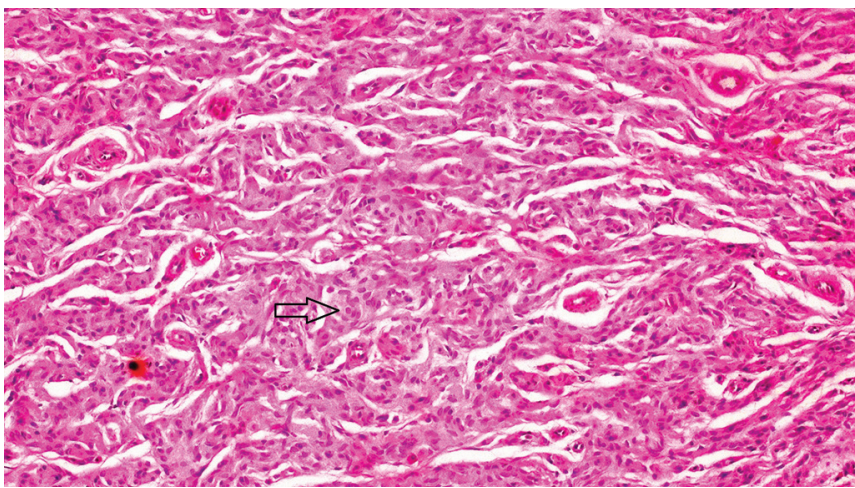

Fig. 4: Spindle cell proliferation

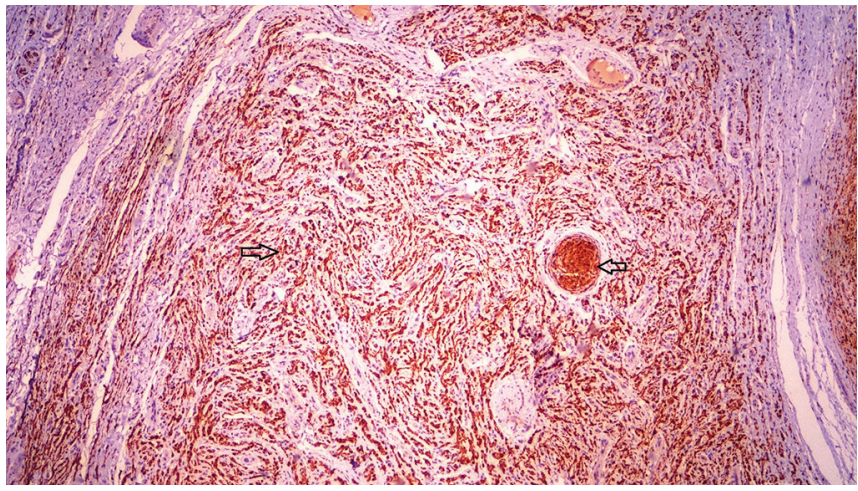

Fig. 6: S-100 positivity of spindle cells

Microscopic examination of Toluidine blue-stained section showed presence of abundant mast cells (Fig. 5).

\section{Immunohistochemistry}

S-100 showed diffuse positive intense expression for tumor cells (Fig. 6). Smooth muscle actin (SMA) was negative (Fig. 7).

Based on clinical features, histopathological and immunohistochemical analysis, diagnosis of PN of tongue was given.

\section{DISCUSSION}

Localized and single NFs often grow and expand along peripheral nerves as well separated, but nonencapsulated

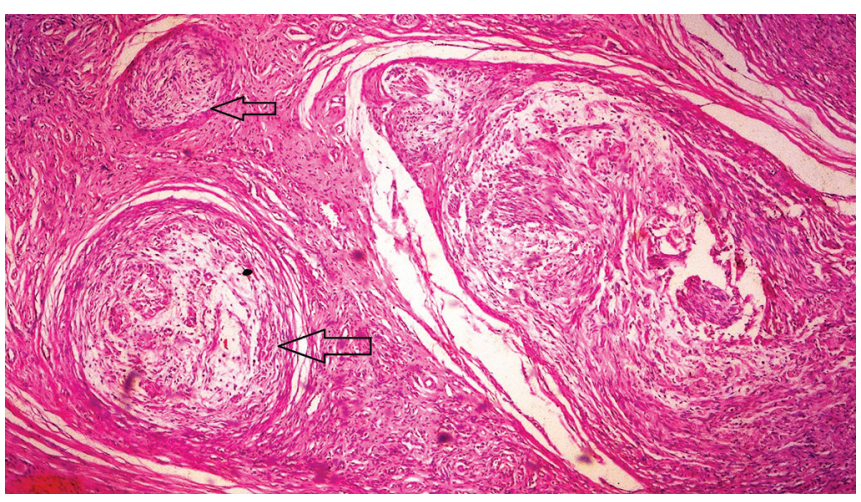

Fig. 3: Nerve bundles

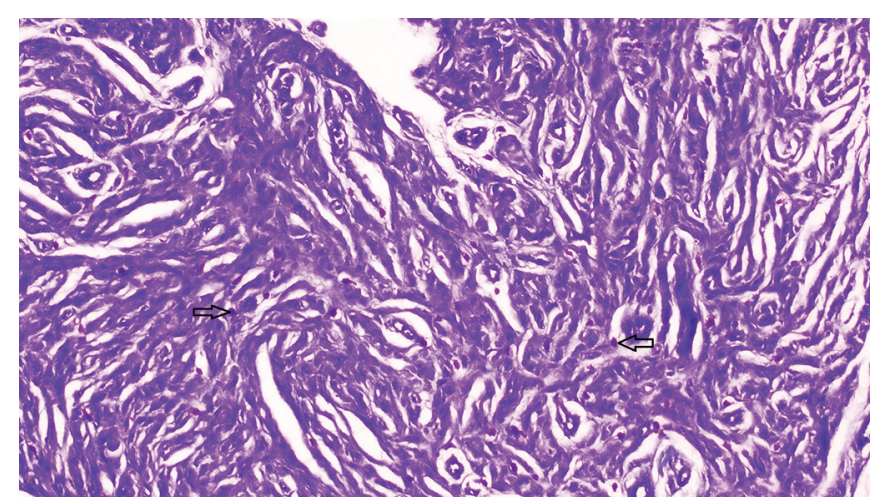

Fig. 5: Toluidine blue stain demonstrating mast cells

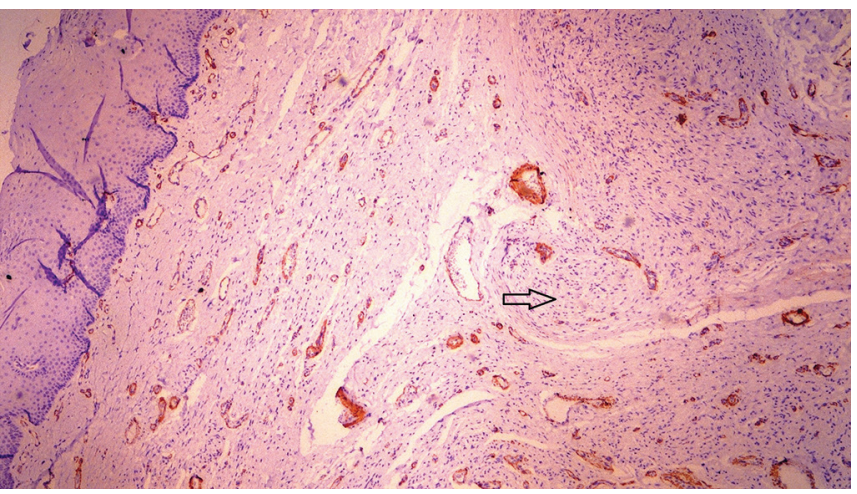

Fig. 7: Smooth muscle actin negative tumor cells

tumors. Very rarely, in tumor area there is necrosis and cystic degeneration. ${ }^{5}$

Plexiform neurofibroma is an unusual histological variant of NF and is described as a benign tumor of nerve sheath origin involving multiple nerve fascicles of the smaller branches of peripheral nerves. Plexiform neurofibroma can be sporadic without systemic or familial involvement. More frequently, however, the condition is generalized as part of NF-1, the most common form of neurofibromatosis. The presence of $\mathrm{PN}$ is considered pathognomonic for NF-1, which is also referred to as "Von Recklinghausen's disease of the skin." Although PN is a dermatologic disorder, it may rarely affect the oral cavity where it has been described in the tongue, oropharynx, 
and cheek mucosa. Some cases in the head and neck region of children affected the major salivary glands. ${ }^{6}$

Oral cavity involvement by a solitary and peripheral PN in patients with no other signs of neurofibromatosis is uncommon, and few cases are described in the submandibular gland, tongue, or adhered to the periosteum at the mental foramen. ${ }^{3}$

The tumor is described as gradually progressive, locally invasive, and often disfiguring. Due to neurovascular involvement with nerve compression, loss of function is possible. In general, PN causes diffuse nodular enlargement of a nerve and its branches by a proliferation of Schwann cells in the nerve sheath across the length of a nerve. ${ }^{6}$

Oral NFs are usually present as submucosal, nontender uninflamed discrete masses that range from few millimeters to several centimeters. Tumors tend to grow slowly, and patients are usually asymptomatic. Common sites of the oral solitary NFs include tongue (26\%), buccal mucosa $(8 \%)$, gingiva $(2 \%)$, alveolar ridge $(2 \%)$, labial mucosa $(8 \%)$, palate $(8 \%)$, nasopharynx, paranasal sinuses, larynx, floor of the mouth, and salivary glands. Tumors may also arise within the bone ${ }^{7}$ and are called central NFs.

Neurofibromas of the large nerves, which appear clinically as soft, drooping, and doughy masses, are benign neoplasms composed of neurites, Schwann cells, and fibroblasts within a collagenous or myxoid matrix. ${ }^{8}$

Histopathological classification of NF:

- Diffuse-It consists of round or slightly pointed Schwann cells located in collagen fiber layer. There are often Wagner Meissner-like structures. The tumor usually grows in dermal and subcutaneous layers spreading over taken area and tissue. They are most frequently located in head and neck tissues.

- Plexiform-It is connected with nerves changing them into extensive intricate masses. It is common in patients suffering from Von Recklinghausen disease (NF-1).

- Epithelioid-NF where most Schwann cells are round or polygonal shaped.

- Pacinian-A type of NF where small round whorled structures resembling Pacinian body-like structures are present as prominent feature. ${ }^{5}$

The histopathological differential diagnosis of neurilemmoma, leiomyoma, and fibrous histiocytoma was considered. Neurilemmoma unlike NF will show encapsulated mass as well as hypercellular and hypocellular areas. S-100 protein immunostaining is strong and uniform in neurilemmoma, whereas there is variable staining of cells with S-100 in NF. ${ }^{9}$

Leiomyoma has a more distinct fascicular growth pattern. Their blunt-ended nuclei are plumper, and the cytoplasm typically has longitudinal striations corresponding to the presence of myofilamentous material, which can be accentuated using Masson trichrome stain. They strongly express SMA and muscle-specific actin in a diffuse pattern. ${ }^{9}$

Fibrous histiocytoma contains mixture of spindle cells and xanthomatous cells which is in contrast with NF. Neurofibroma contains a population of Schwann cells expressing S-100 protein and having a serpentine nuclei. ${ }^{9}$

The basic components of an evolving NF are (i) Nf1-/Schwann cells, which act as tumorigenic instigators; (ii) Nf1+/- mast cells, which act as inducers; and (iii) Nf1+/- fibroblasts, Schwann cells, perineural cells, and endothelial cells, which act as the responders. The pathways of NF formation as identified by Yang et al involve Kit ligand (secreted by Nf1-/- Schwann cells), c-Kit receptor (expressed by mast cells), a4b1 integrin (a mast cell surface protein), vascular cell adhesion molecule 1 (an endothelial receptor for a4b1 integrin), Ras (a substrate for neurofibromin), and the class IAphosphoinositide 3-kinase-Rac2 pathway (mast cell transduction downstream of activated Ras). The primary observation of Yang et al is the enhanced migration of neurofibromin haplo insufficient mast cells toward the double-inactivated Nf1-/-Schwann cells that secrete five times the normal levels of Kit ligand. According to this paradigm, in human NFs, a "second hit," or somatic mutation of the normal NF-1 tumor suppressor gene allele in heterozygous Schwann cells as a random event, is the initiating event which sets the stage for mast cells to induce NF formation by paracrine/autocrine mechanisms. ${ }^{10}$

Imaging techniques are not diagnostic. However, magnetic resonance imaging gives more information about the limits and extension of the tumor than a computed tomography scan. Fine-needle aspiration biopsy is not diagnostic. Definitive diagnosis rests upon histological study. Small axons all over the tumoral tissue are demonstrated with silver staining. S-100 protein too had been demonstrated with immunohistochemical techniques. ${ }^{11}$

\section{CONCLUSION}

Most NFs in head and neck region tend to be solitary tumors, but the occurrence of isolated PN affecting peripheral nerves without association with NF-1 is unusual in oral cavity. ${ }^{3}$ Isolated $\mathrm{PN}$ is a rare tumor. The present case is an isolated $\mathrm{PN}$ of the tongue that was not associated with neurofibromatosis and treated with surgical excision.

\section{CLINICAL SIGNIFICANCE}

Neurofibromas may exhibit sarcomatous alteration in 3 to $15 \%$ of cases, especially in multiple neurofibromatosis. 
Solitary NFs rarely change into a malignant form. However, Steward and Bailey have drawn attention to the fact that it is important to know whether the tumor is benign or malignant before excision. ${ }^{12}$

\section{REFERENCES}

1. Gnepp, DR. Diagnostic surgical pathology of the head and neck. Elsevier Health Sciences; 2009. p. 246.

2. Suramya S, Shashikumar P, Shreeshyla HS, Kumar S. Solitary plexiform neurofibroma of the gingiva: unique presentation in the oral cavity. J Clin Diagn Res 2013 Sep;7(9): 2090-2092.

3. Marocchio LS, Pereira MC, Soares CT, Oliveira DT. Oral plexiform neurofibroma not associated with neurofibromatosis type I: case report. J Oral Sci 2006 Sep;48(3):157-160.

4. Campos MS, Fontes A, Marocchio LS, Nunes FD, de Sousa SC. Clinicopathologic and immunohistochemical features of oral neurofibroma. Acta Odontol Scand 2012 Dec;70(6): 577-582.
5. Komorski J, Petz L, Nienartowicz J, Pałka Ł. Neurofibroma of sinus maxillae. Otolaryngol Pol 2014 Apr 30;68(2):94-98.

6. Zwane NP, Noffke CE, Raubenheimer EJ. Solitary oral plexiform neurofibroma: review of literature and report of a case. Oral Oncol 2011 Jun 30;47(6):449-451.

7. Sivapathasundharam B, Lavanya S, Saravanakumar R, Ahathya RS. Solitary neurofibroma of the gingiva. J Oral Maxillofac Pathol 2004 Jul 1;8(2):107-109.

8. Sharma A, Sengupta P, Das AK. Isolated plexiform neurofibroma of the tongue. J Lab Physicians 2013 Jul 1;5(2):127-129.

9. Goldblum JR, Weiss SW, Folpe AL. Enzinger and Weiss's soft tissue tumors. Elsevier Health Sciences; 2013.

10. Viskochil DH. It takes two to tango: mast cell and Schwann cell interactions in neurofibromas. J Clin Investig 2003 Dec 15;112(12):1791-1793.

11. Rajendran R. Plexiform neurofibroma of the gingiva: report of a rare case. J Oral Maxillofac Pathol 2006 Jan 1;10(1):28-30.

12. Alatli C, Öner B, Ünür M, Erseven G. Solitary plexiform neurofibroma of the oral cavity: a case report. Int J Oral Maxillofac Surg 1996 Oct 1;25(5):379-380. 